\title{
Some Problems of Hybrid Poplar Selection and Management in Ontario
}

\author{
L. ZSUFFA \\ Research Scientist, \\ Forest Research Branch, \\ Ontario Ministry of Natural Resources, \\ Maple, Ontario \\ Contribution No. 1004
}

\section{Ontario's Poplar Breeding and Management Program}

The poplar breeding program in Ontario, encompassing native species of poplar and many exotics, is aimed at the selection of vigorous hybrids that can be utilized as clones (Heimburger, 1968; Zufa, 1969a). In the late sixties, a good market for hardwood pulp in eastern Ontario and the availability of land resulted in a demand for such hybrid poplar clones, but proven clones of Ontario origin were not yet available. To seize the interest of management and industry, a number of recognized (Populus $\mathrm{x}$ euramericana (Dode) Guinier) clones were imported from Europe and after several years of testing for frost-hardiness and site tolerance, they were released for planting. Silvicultural methods were developed to grow poplars on a variety of sites. With a continuing breeding program, even better hybrids will result.

Most poplar planting is for pulpwood trees (approximately $7 \mathrm{in}$. $\mathrm{dbh}$ and $50 \mathrm{ft}$ in height) on a 10 -year rotation at $10 \mathrm{ft} \times 10 \mathrm{ft}$ spacing (Zsuffa 1973). A new concept is to produce fibre on densely-grown, annually or bi-annually harvested poplar coppices (Zsuffa and Anderson 1974). Mean annual increments of $300 \mathrm{ft}^{3} /$ acre in a 10 year-rotation and $600 \mathrm{ft}^{3} /$ acre in a 1- or 2-year coppice rotation were obtained in test plantations. Such yields seem realistic in large-scale production. The pulp quality of this fast-grown wood compares satisfactorily with regular poplar.

Some plantation failures have occurred. These have resulted from problems with clonal selection and silvicultural management.

\section{Poplar Clonal Selection Problems}

Difficulties in clonal selection of poplar are encountered because of the time element and the effect of environment.

\section{The time element}

We are pressed by time to judge the trees on the basis of early performance. Some silviculturally important characteristics such as rooting ability, stem-form and branching-habit are ob-
Fast-growing clones of poplar can be quickly reproduced by vegetative propagation. This is the basis for a short-rotation plantation program in fibre-deficient southeastern Ontario.

vious in the juvenile stage of poplar trees. Rooting ability can be determined in planting trials of cuttings in the nursery and in the field. The stemform and branching-habit can be detected early and the juvenile-mature correlations in this regard are strong (Zufa 1969b).

Other important characteristics change with the age of trees, for example the fibre quality and the specific gravity of the wood. This causes problems in early selection. Correlations between juvenile and mature wood characteristics could serve as criteria for early selection, but little is known about them.

Difficulties may also occur in early selection for disease resistance. While the reaction of trees to some diseases, such as leaf rust (Melampsora medusae Thüm.), is obvious in nursery stock, other diseases such as some cankers (Septoria musiva $\mathrm{Pk}$. and Hypoxylon pruinatum (Klotzch) Cke.) and the leaf blight (Plagiostoma populi sp. nov.) occur only on larger, more mature trees. The criteria for early testing of these latter diseases would be important, but very difficult to develop. Attempts are being made to find indicators of resistance in chemical components of wood (Hubbes 1969).

The growth rate of clones changes with age. Some clones show very vigorous growth in the nursery and during the first few years in the plantation. Other clones grow more moderately at the beginning, but sometimes they outperform the early fast-growers in the later years. In a test plantation, the ranking of clones changed considerably during the first 6 years of plantation age (Figure 1).

This meant that several years of observation were needed for proper clonal selection. Figure 1 also shows that specific clones should be selected for specific rotations. Clearly, for a 1- to 3-year coppice rotation the "fast-starter" clones would be well suited, whereas the longer rotations might require different clones.

\section{The effect of environment}

In clonal selection, we are interested in several characteristics. It is easy to select for 


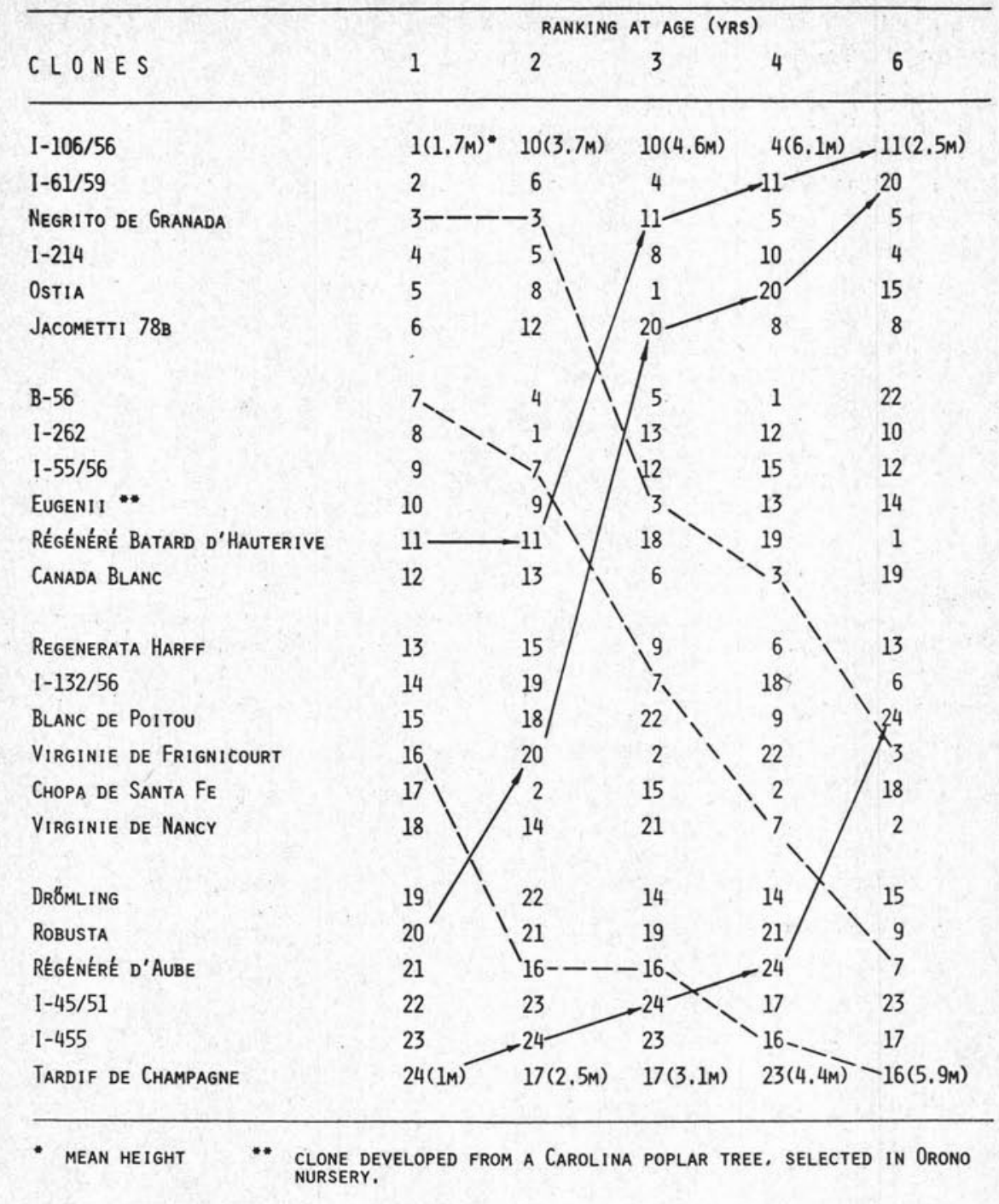

Figure 1. Ranking of clones according to mean heights at Huronia District, Flos Twp, Ontario $\left(44^{\circ} 10^{\prime} \mathrm{N}, 80^{\circ} \mathrm{W}\right)$ clonal test established in the spring of 1969 , on Tioga loamy sand, at $10 \times 10 \mathrm{ft}$ $(3 \times 3 \mathrm{~m})$ spacing. All clones in the test are of Populus $x$ euramericana (Dode) Guinier $(=P$. deltoides Bartr. $\times$ P. nigra L.) origin. The solid and broken lines indicate the changes in ranking of some clones.

rooting ability, stem-form and branching-habit. However, it is more difficult to select for growth, frost and pest resistance, and wood quality because of the smaller degree of genetic control and the larger amount of environmental influence.

Various poplar clones differ in their site requirements. The basic differences in performance are due to species origin. However, considerable clonal variation exists even within each species group: in the test plantation clones of the same species origin varied in growth by more than $50 \%$ (Fig. 1). Some clones grew relatively well on a number of sites, whereas others performed extremely well on some sites, but showed poor growth on other sites (Zsuffa and Zivanov, 1966).

The effect of site on the tree performance may change with time. For example, after several years of good growth during comparable weather conditions, a sudden change to either excessively dry or to humid weather has caused not only interruptions in growth, but also the appearance of saprophytic diseases. Similarly, a sudden change in temperature, especially during the winter period, has resulted in frost damage, winter drying, and diseases caused by Cytospora chrysoperma (Pers) Fr. and Dothichiza populea Sacc. et Br. which appear the following spring. Some clones are more affected than others. On a soil of restricted fertility, the growth of trees of certain clones slowed down when the root systems had exploited all of the fertile horizons. In such cases, the initial fast growth was misleading with respect to site potential. All of these examples point to the importance of the time element in selection, even when considering the effects of site.

\section{Poplar Management Problems}

The problems of poplar management, on which the success of the plantation depends, fall into two main categories: those related to the selection of the right clones, and those dependant on securing the right conditions for growth.

Not even the best management techniques can secure good growth if the clones are not adapted to the site and type of culture. Clones react differently, not only to sites but also to the type of culture. The species origin of clones will give general indications of their suitability for certain cultural systems. Hybrid cottonwoods are more suited to intensive management, while aspens and balsam poplars grow satisfactorily in forest stand conditions. However considerable clonal variation occurs even among the clones of the same species origin. Clones which have rela- 
tive narrow adaptability are better suited for intensive management while clones with broad adaptability are desired for forest stand conditions. The fast starter clones will be especially useful for very short rotation management. Production trials are needed to test the suitability of various clones for various management systems. However, the problem of clonal selection is not the only one on which the success of the operation depends.

In the management of such an intolerant and demanding tree as hybrid poplar, one must have the right soil conditions and control competitive weeds. In production trials in southeastern Ontario, we have used mechanical site preparation, soil cultivation and herbicides.

Before the hybrid poplar program becomes fully operational many other aspects in addition to clonal selection and site control will have to be worked out, e.g., type of planting stock, spacing, harvesting techniques and coppice regeneration. The mechanization of planting, tending and harvesting is also necessary. The outstanding potential of hybrid poplar clones makes the solution of these problems a challenge.

\section{Conclusions}

This brief presentation of the problem of hybrid poplar clonal selection and management has demonstrated that:

close co-operation of tree breeders and forest managers is needed for the selection of suitable clones and to learn how to manage them; the selection must be based on several years of observations in clonal tests replicated by site; specific clones are needed for specific sites, rotations and management systems.

\section{References}

Heimburger, C. 1968. Poplar breeding in Canada. In: Maini, J. S. and J. H. Cayford, Eds., Growth and utilization of poplars in Canada. Can. Dep. For. Rural Develop., For. Br., Publ. 1205. pp 88-100.

Hubbes, M. 1969. Benzoic and salicylic acids isolated from a glycoside of aspen bark and their effect on Hypoxylon pruinatum. Can. J. Bot. 47(8):1295-1302.

Zsuffa, L. 1973. Hybrid poplar pulpwood production trials in southeastern Ontario. For. Chron. 49(3):125.

Zsuffa, L. and H. Anderson. 1974. New culture and utilization concepts show promise. Poplar Council North Amer. News, Fall. 1974:4-5.

Zufa, L. 1969a. Poplar breeding in Canada. For. Chron. 45(6): $402-408$.

Zufa, L. 1969b. The heritability of the stem form of black poplar (Populus nigra L.). 2nd World Consultation Forest Tree Breeding, Washington, Aug. 7-16, 1969. FAO/FTB-693/7. 11 pp. (mimeo).

Zufa, L. and N. Zivanov. 1966. Indicators of a significant and specific correlation between the poplar clones and soil types. Sumarski list 90 (1-2):137-148 (in Yugoslav, with French summary).

\section{Tree Improvement - A Company Viewpoint}

\section{H. JENSEN}

Project Forester,

Tahsis Co. Ltd.,

Gold River, B.C.

The trend in British Columbia is towards intensive management. Since the application of tree improvement principles is essential to intensive management, the major B.C. companies with large timber holdings or Tree Farm Licenses have started their own tree improvement programs, particularly in the intensively-managed coastal forests.

At the beginning, it was recognized that cooperation between industry. government, and university was essential. Thus, the 'Plus Tree Board' was formed in 1959. This board set the quidelines and promoted the selection of Douglasfir (Pseudotsuga menziesii (Mirb.) Franco plus trees. The Plus Tree Board was later renamed 'The Tree Improvement Board' and the objectives were expanded to cover all aspects of tree improvement.

General meetings are held once a year and workshops conducted as needed. Recently, workshops have been held in seed orchard management and in the selection of hemlock plus trees. This year, sub-committees are working on a review of seed zones for the Vancouver Forest
District, locating suitable land for seed orchards, and the preparation of a proposal for a co-operative industrial tree improvement agency.

The industrial members of this board are B.C. Forest Products Ltd., Canadian Forest Products Ltd., Crown Zellerbach Co. Ltd., MacMillan Bloedel Co. Ltd., Pacific Logging Co. Ltd., Rayonier Co. Ltd., Tahsis Co. Ltd., and Weldwood Co. Ltd. All of them have embarked on tree improvement programs of varying scope and size. Co-operative projects have been undertaken and funded by these companies. Some of the projects are plus tree selections of Douglas-fir, western hemlock (Tsuga heterophylla (Raf.) Sarg. and Sitka spruce (Picea sitchensis (Bong.) Carr.; phenological studies of Douglas-fir; studies of grafting techniques; and assessment of scion-rootstock incompatibility of grafted Douglas-fir selections.

Most of the industrial members are committed to the selection and preservation of superior trees as base breeding populations and the development of first-generation orchards to meet current reforestation seed needs. Gains of 10 to $15 \%$ or more are expected from these orchards.

I have worked with the Tahsis Co. for 10 years; a company which has a firm belief in the value of genetics in forestry. Primarily through 